\title{
Policy Implications and Analysis of the Determinants of Travel Mode Choice: An Application of Choice Experiments to Metropolitan Costa Rica
}

\author{
Francisco Alpizar \\ Fredrik Carlsson ${ }^{\mathrm{A}}$ \\ Working Papers in Economics no. 56 \\ September 2001 \\ Department of Economics \\ Göteborg University
}

\begin{abstract}
In this paper we study a group of policies aimed at discouraging the use of private transportation during peak hours, both directly and indirectly, by increasing the attractiveness of the only available substitute, the bus. This is done using a choice experiment constructed to find the answer to the following basic question: Given fixed house-to-work structures and no working hour flexibility, by how much is the choice of travel mode for commuters to work sensitive to changes in travel time, changes in costs for each mode and other service attributes? This information is then used to identify the most suitable combination of policies dealing with air pollution and congestion in the typical developing country context of metropolitan Costa Rica. We also provide estimates of the value of travel time as a measure of the potential benefits gained from reduced congestion.
\end{abstract}

Keywords: Choice experiment; Random Parameter Logit; urban air pollution; congestion.

JEL-classification: C25, R41.

We have received valuable comments from Olof Johansson-Stenman, Peter Martinsson, Thomas Sterner, Sharon Kuhlman and Victor Castillo and seminar participants at Gothenburg University. Financial support from the Swedish International Development Agency and the Bank of Sweden Tercentenary Foundation is gratefully acknowledged.

${ }^{A}$ Department of Economics, Gothenburg University, Box 640, SE-405 30 Gothenburg, Sweden. E-mail:

Francisco.Alpizar@economics.gu.se,Fredrik.Carlsson@economics.gu.se. 


\section{Introduction}

The last 20 years have been characterized by a dramatic increase in the urban populations of most developing countries. Even small countries like the ones in Central America now have metropolitan areas that surpass one million inhabitants. This increase, in combination with a lack of urban planning and an inefficient transportation system, causes problems of decreased air quality in urban environments (World Bank, 1996). The pollution is associated with a wide variety of health problems (respiratory problems, cancer, blood poisoning), deterioration of buildings, acid rain and global warming. Traffic congestion further complicates matters since it not only imposes high costs in terms of lost time and high stress, but also increases emissions by decreasing the speed of travel.

The main objective of this study is to contribute to the design of policies dealing with the problems of congestion and air pollution in the urban context of a typical developing country. We study the determinants of the choice of transport mode, bus versus car, for work trips in the short run, where we treat the number of trips as exogenously given. This is done with a choice experiment conducted on car commuters. These commuters are responsible for the worst congestion and pollution during peak hours, and at the same time are the ones who can most easily switch to public modes of transportation. We explore a combination of policies aimed at increasing the cost of private transportation, specifically increased fuel and parking costs, and policies aimed at improving public transportation; in this case reduced travel time, subsidized fares and improved quality of the service. The joint implementation of these policies aims at reducing congestion and pollution, especially during peak hours, by restraining demand for private transportation while providing a suitable substitute. Currently the Costa Rican government is involved in a program to improve and restructure the public transportation system, emphasizing the type and quality of service provided. One of the aims of this program is to achieve a reduction in the level of congestion and pollution originating from urban transportation. Therefore, our survey is also a test of the ability of such a system to detract customers from private transportation.

\section{Environmental Regulation of Transport in a Developing Country Context}

Both market-based and command and control policies require strong and stable institutions, adequate legislation and effective monitoring and enforcement. Many developing countries have weak institutions and unclear legislation, resulting in ineffective monitoring and enforcement of policies. Furthermore, in many cases there is a weak political commitment to environmental goals, which means that resistance to environmental measures is likely to be successful. In addition, uncertainty about the permanence of environmental regulations causes an inefficient adaptation to the long run incentives of any given policy (O'Connor, 1999; Huber et al., 1998; Eskeland and Jimenez, 1992). In this context it may be particularly important to revise the perspective of environmental regulations by emphasizing their short run effects, and identifying ways of reducing the potential resistance against certain types of policies (see e.g. Harrington et al. 1998).

The regulation of the urban transport system, intended to reduce congestion and pollution, requires a combination of policies targeting the different interrelated components of that system. On one hand, regulating private transportation requires a number of policies that can, 
more or less, mimic the properties of the first-best solution. ${ }^{1}$ A first-best policy such as a differentiated road charge (see e.g. Johansson 1997) is not yet economically feasible with the present technology. On the other hand, public transportation is often regulated in terms of the fee system, routes, number of departures, etc. The design of the public transportation system is, consequently, both a technical and a political decision, and decision makers need information regarding which characteristics of this service are most relevant to travelers. This is particularly relevant if there is a wish to shift travelers from private to public transportation, and if there is a need to provide travelers with an acceptable alternative mode, as a way to increase the acceptance of the environmental regulations.

There are two interrelated sources of reductions of the environmental impact from urban transportation: (i) a decrease in the emissions per kilometer driven, and (ii) a decrease in the number of kilometers driven. In this paper we focus on policies aimed at reducing the amount of private trips, by promoting a change from private to public modes of transportation, for a given structure of car ownership and house-to-work locations. These policies include the complementary application of instruments to reduce the number of private trips by increasing the cost per journey, as well as the provision of an improved system of public transport. Fewer trips entail not only a reduction in the number of kilometers driven, but also less congestion and, consequently, fewer emissions per kilometer. In the long run, drivers can buy smaller and more fuel efficient cars, or even move closer to work in response to more expensive travel.

An increase in the cost per trip for the private mode is expected to have two effects in the short run. First, there will be a reduction in the overall number of trips, since some trips will not take place, and second there will be a substitution towards public transport. In the case of trips to work, we expect the first effect to be small. A substitution from private to public transportation is expected to have two further effects: (i) a reduction in congestion levels, which has a direct effect on emissions and (ii) if the new passengers could be accommodated by the existing bus journeys, then passengers per bus trip would increase. The more passengers per bus, the lower the emissions per passenger. For the particular case of Costa Rica, buses run during peak hours with an average load of approximately two thirds of their capacity, so a marginal mode switch is not expected to raise the number of bus journeys required to cope with the increase in demand (Ministry of Public Infrastructure and Transport, 1999). Note also that a well-organized and efficient system of public transportation does not necessarily require additional bus trips. By restructuring the number of routes into a trunk and feeding system, as planned in Costa Rica, fewer buses will enter the city center, therefore reducing pollution and congestion. In cities where buses run with approximately full loads, the number of bus journeys might increase due to increased demand. In such a case, the net benefit of a mode switch might not necessarily be positive.

Policies aimed at decreasing private transportation by means of increased costs include fuel taxes, parking fees and road tolls in city centers. The last two are particularly relevant for tackling congestion, since they directly raise the cost of entering the city. As discussed by Small (1992), increased parking costs are likely to have a substantial effect on private

\footnotetext{
${ }^{1}$ See for example Johnstone and Karousakis, 1999; Fullerton and West, 2001; Eskeland and Devarajan, 1996. For a treatment of optimal policies of both private and public transportation, including a supply decision, see De Borger et al. (1996) and De Borger and Wouters (1998)
} 
transport, inducing both carpooling and a substitution towards public transportation. (see e.g. Willson and Shoup, 1990). Fuel taxes have been successful in reducing fuel demand in many countries, although public perception about them is negative (Sterner, 1994; Thomson, 1998). As we have discussed, one way to reduce the political opposition to such measures is to provide a suitable system of public transportation. The design and quality of the public transportation system is thus an important factor itself in decreasing the use of private transportation, by providing a suitable substitute to the private mode. Some measures include a reallocation of road space favoring exclusive "right of way" for buses in order to reduce travel time, enhanced safety and comfort on board and improved scheduling and punctuality in order to reduce waiting times.

\section{Urban transport in Costa Rica}

Almost half of the population and most of the economic and governmental activity in Costa Rica is located in the metropolitan areas of San José, Alajuela, Cartago and Heredia. The city of San José, the capital, serves as a bridge between the others and shows signs of a collapse in its transport infrastructure, ${ }^{2}$ particularly during the peak hours of the morning (7 to 9 am) and the evening (5 to 8pm). The roads linking the other cities to San José have also reached severe congestion levels. Most inhabitants of metropolitan Costa Rica are exposed daily to very high pollution levels, with road transportation contributing more than $80 \%$ of the total air pollution in metropolitan San José (Alfaro, 1999). A survey conducted by the Ministry of Health identified respiratory and pulmonary illnesses as the most common causes for visiting the public health hospitals (Ministry of Health, 1997).

Government reactions have been mostly limited to the provision of new infrastructure. Unfortunately, the capacity of the additional infrastructure is overflowed sometimes even before its construction is completed, in an extreme example of the so-called "law of highway congestion". Even if this does not occur, it is likely that the government focus on providing infrastructure to private users causes negative network externalities for the public transportation sector, due to increasing returns to scale in public transportation (see e.g. Small, 1992).

In recent years there have been some attempts to tackle the problem of air pollution, mostly by using command and control measures to reduce the amount of emissions per kilometer. As of 1995, all new cars are required to have a working catalytic converter, and lead was eliminated from fuels in 1996. Also in 1996, the government introduced emissions standards for all vehicles. These standards were, however, not very strict and most cars passed the tests without any adjustment. There is therefore little evidence that this policy has had any effect on emissions (Pujol, 1996; Jiménez, 1997). The tax structure for car ownership has had perverse effects on the generation of pollution (Echeverría and Solórzano, 2000). First, in 1986 the government restructured the import tariffs for private vehicles so that cars that were 5 years old were paying around $30 \%$, whereas new cars paid a $100 \%$ tariff. The impact of this policy was dramatic. By the end of 1997, 72\% of the car fleet for private use was more than 10

\footnotetext{
${ }^{2}$ Although approximately $70 \%$ of all trips are made using the bus mode (mostly low and middle-low income individuals), the number of commuters in private modes surpasses the capacity of the available infrastructure. Furthermore, there are institutional and geographical limitations to the expansion of the road network.
} 
years old (RECOPE, 1999). In the last two years the government has tried to reduce this distortion despite opposition from the affected parties; mainly used cars dealers. Second, the yearly road tax is calculated based on the value of the car, disregarding its impact on infrastructure or the environment. Therefore, newer cars, which are more fuel-efficient and generate fewer emissions, are subject to higher taxes than older vehicles.

Car ownership and fuel consumption have been increasing at high rates. Between 1989 and 1999, the car fleet grew at an average rate of $7.6 \%$ per year, ${ }^{3}$ with gasoline and diesel use increasing at an average rate of $10.4 \%$ and $7 \%$ per year, respectively. In the same period, per capita GDP increased, on average, 2.2\% per year (Proyecto Estado de la Nación, 1999). The main factors behind this development are most likely the declining real price of fuel, the perverse tax structure for car ownership and the lack of an adequate system of public transportation. As of 1999, real prices on all fuels were slightly lower than in 1988, with an average yearly growth of $0.02 \%$ in that period. The main reason for these policies is that cheap transportation has been identified as crucial for economic development and prosperity. Furthermore, politically, measures to reduce the demand for private transportation are seen as too costly in terms of votes, since most of the benefits of such policies are mainly realized in the long term.

On the other hand, the public transportation system is underdeveloped. The government has paid little attention to its quality and service. Many times companies operating similar routes find themselves competing for passengers along the same street, with most routes leading all the way to the center of the capital (i.e. a radial system). This has resulted in deteriorating levels of service and congestion deadlocks in the city center at peak hours. Fares have been determined by the regulatory authority based on basic operating costs, paying little attention to the quality and type of service provided. Now, the Ministry of Transportation is trying to organize the sector by restructuring the number of routes into a trunk and feeding system. Furthermore, companies will face higher standards regarding the vintage of buses. The new program also provides economic incentives to bus companies that comply with the new regulations. Bus fares will be linked to an evaluation of the service provided, as measured by: (i) travel time, i.e., compliance with number of departures and scheduling reliability; (ii) quality, defined as comfort, safety and sanitation; (iii) accessibility and maintenance of bus stops; and (iv) provision of information about routes and timetables. If the project becomes a reality, it will imply better buses, better quality of service, less congestion due to fewer buses entering the city center and potentially shorter travel times. As mentioned in the introduction, our survey then is also a test of the ability of such a system to attract new customers away from private transport.

\section{Mode Choice Experiments}

In order to evaluate the potential impact of different policies on the substitution between private and public transportation, information regarding traveler preferences for the attributes of the transport system is needed. Since some of the attributes of interest do not exist today, it

\footnotetext{
${ }^{3}$ The car fleet doubled from 1978 to 1988 and doubled again from 1988 to 1998 . Approximately $75 \%$ of the fleet is for private use (RECOPE, 1999). According to a recent local newspaper survey, $47 \%$ of all households own at least one vehicle. This data refer to the whole country, and the numbers are probably much higher in the metropolitan area.
} 
is not possible to rely only on revealed preference data for that purpose. Therefore, we conduct a mode choice experiment evaluating traveler preferences for different attributes of both private and public transportation. The basic idea behind a mode choice experiment is to create a hypothetical situation and elicit the preferences of commuters for different attributes, through their choice of mode of transport in each of those situations. Choice experiments have a long tradition in transport economics, where they have been developed as a complement to revealed preference studies, because of the possibilities of analyzing preferences for new levels of attributes (for an overview see Polak and Jones, 1997). The roots of choice experiments can be traced back to Lancaster's (1966) microeconomic theory of demand for characteristics of goods, and the Random Utility Theory (Thurstone, 1927; McFadden, 1973). ${ }^{4}$

We assume that the utility derived from each of the two alternatives available, car and bus, depends mainly on the attributes selected to describe those alternatives, and that a respondent $q$ will choose to go by bus for a given trip if and only if

$$
V_{B q}\left(x_{B q}, y_{q}, s_{q}, \varepsilon_{B q}\right)>V_{C q}\left(x_{C q}, y_{q}, s_{q}, \varepsilon_{C q}\right)
$$

where $V_{i q}$ is the indirect utility function for individual $q$ if alternative $i$ is chosen, $x_{i q}$ is the vector of $K$ attributes (including costs) that constitutes the profile of alternative $i, y_{q}$ is the individual's income, $s$ is a vector of $q$ 's socio-demographic characteristics and $\varepsilon_{i q}$ is a stochastic component that reflects observational deficiencies arising from unobservable components, such as characteristics of the individual or non-included attributes of the alternatives in the experiment, measurement error and/or heterogeneity of preferences. In choice experiments, the respondents face a sequence of such decisions, where each decision set (indexed by $t$ ) contains different profiles of the alternatives. The objective of the survey is to obtain estimates of the coefficients for all the relevant attributes, based on the trade-offs made by the respondents when faced with successive hypothetical situations.

In this paper we apply a general type of model called Random Parameter Models, where taste variation among individuals is explicitly treated (see e.g. Bhat, 2000; Train, 1998). We use a linear latent indirect utility function $U$, consisting of a systematic and a stochastic part:

$$
U_{i q t}=\alpha_{i q}+\gamma_{i} s_{q}+\beta_{i q} x_{i q t}+\varepsilon_{i q t}
$$

where $\alpha_{i q}$ captures an intrinsic preference of individual $q$ for alternative $i, \gamma_{i} s_{q}$ captures systematic preference heterogeneity as a function of socio-demographic characteristics, $x_{i q t}$ is the vector of attributes (including the cost) describing alternative $i$ for individual $q$, in the choice situation $t$. The vector of coefficients $\beta_{i q}$ is assumed to vary in the population, with probability density given by $f(\beta \mid \theta)$, where $\theta$ is a vector of the true parameters of the taste distribution.

The probability that individual $q$ chooses alternative $i$ in a choice situation $t$, conditional on $\beta_{i q}$, is given by:

\footnotetext{
${ }^{4}$ For a detailed presentation of choice experiments see e.g. Alpizar et al. (2001); Louviere et al. (2000).
} 


$$
P_{q}\left(i t \mid \beta_{q}\right)=P\left\{\left(\alpha_{i q}+\gamma_{i} s_{q}+\beta_{i q} x_{i q t}+\varepsilon_{i q t}\right)>\left(\alpha_{j q}+\gamma_{j} s_{q}+\beta_{j q} x_{j q t}+\varepsilon_{j q t}\right) \forall j \in \mathbf{A}_{t}\right\}
$$

where $\mathbf{A}_{t}=\left\{A_{C}, A_{B}\right\}$ is the two alternatives, bus and car, available in choice situation $t$. If the $\varepsilon^{\prime} s$ are IID type I extreme value, the probability of equation (3) can be calculated as

$$
P_{q}\left(i t \mid \beta_{q}\right)=\frac{\exp \left(\alpha_{i q}+\gamma_{i} s_{q}+\beta_{i q} x_{i q t}\right)}{\sum_{j \in \mathbf{A}_{t}} \exp \left(\alpha_{j q}+\gamma_{j} s_{q}+\beta_{j q} x_{j q t}\right)}
$$

The conditional probability of observing a sequence of choice decisions from individual $q$, denoted $j(q, t)$, from the succession of $M$-hypothetical choice situations in the survey, is the product of standard logit probabilities:

$$
S_{q}\left(\beta_{q}\right)=\prod_{t}^{M} P_{q}\left(j(q, t) t \mid \beta_{q}\right)
$$

Finally, the unconditional probability for a sequence of choices for individual $q$ is then the integral of the conditional probability in (5) over all values of $\beta_{q}$ :

$$
P_{q}(\theta)=\int S_{q}(\beta) f(\beta \mid \theta) d \beta
$$

In this simple form, the utility coefficients vary across individuals, but are constant across the choice situations for each individual. This reflects an underlying assumption of stable preference structures for all individuals (Train, 1998). The integral in (6) generally cannot be evaluated analytically, and we have to rely on a simulation method for the probabilities. Here we will use a simulated maximum likelihood estimator, using Halton draws, to estimate the models (see Revelt and Train 1998, Train 1999).

An important element of these Random Parameter Models is the assumption regarding the distribution of each of the $K$ random coefficients. In this paper we use two alternative formulations. The first assumption is a normal distribution, i.e. that the coefficient for the $k$ attribute is given by $\beta_{k} \sim N\left[b_{k}, w_{k}\right]$. However, a coefficient might then be negative for some individuals and positive for others. For most of the variables in this mode choice experiment it is more reasonable to expect that all respondents have the same coefficient sign. For example, the coefficient on travel time should always be non-positive. For this type of coefficient, a more reasonable assumption would be to assume a log-normal distribution. In this case, the log-normal coefficients have the following form:

$$
\beta_{k q}= \pm \exp \left(b_{k}+v_{k q}\right)
$$

where the sign of coefficient $\beta_{k}$ is determined by the researcher according to expectations, $b_{k}$ is constant and the same for all individuals, and $v_{k q}$ is normally distributed across individuals with mean and variance equal to 0 and $\sigma_{k}^{2}$, respectively. This means that the coefficient has 
the following properties: a) median $=\exp \left(b_{k}\right)$; b) mean $=\exp \left(b_{k}+\sigma_{k}^{2} / 2\right)$; and c) standard deviation $=\exp \left(b_{k}+\sigma_{k}^{2} / 2\right)\left(\exp \left(\sigma_{k}^{2}\right)-1\right)^{0.5}$. For a more detailed treatment of preference heterogeneity, see for example Bhat $(1998,2000)$.

\section{The Mode Choice Survey}

The population used in the survey is individuals with work that have access to a car, and that are living and working in the metropolitan area of San Jose. The reason is that we want to ensure that the respondents can actually make a choice, in the short run, between private and public transportation. As we have discussed, some policies can also have an effect on the decision of owning a car or not, but that effect is not included in this study. This sampling strategy excludes the low-income segments of society from our study, since they cannot afford to own a car. We also focus on work trips since they, in particular, contribute to congestion problems at peak hours. Consequently, we investigate the effect of different policies on the behavior of individuals who work and have access to a car. In our experiment the length and destination of work trips is assumed to be fixed. Additionally, the timing of the trips is assumed to be exogenous, i.e. we do not allow the commuters to adjust their schedule in response to the hypothetical situation presented in the experiment. This might be a limitation of our study (see Small, 1982). Nevertheless, since in Costa Rica there is very little work-hour flexibility, both in the public and private sector, we expect that our results will not be greatly affected by these assumptions. Finally, we restrict the sample to work trips with an origin and destination within the metropolitan area, in order to restrict the analysis to the urban bus system. One limitation of our analysis is that it is partial in nature. For example, our estimates of cost elasticities cannot be regarded as the overall price elasticity of transport demand for metropolitan San José. Even in the short run, individuals can adjust to higher costs per car trip by carpooling and reductions in non-work trips, among other possibilities. It is actually reasonable to expect that people will reduce the number of trips starting with the less important ones (mainly non-work trips). All of these elements hint to significantly larger effects of the policies that we analyze.

A survey company conducted the survey between September 1st and October 30 2000. All interviews were personal interviews where the enumerator read the questions aloud. The respondents were visited at their homes after office hours. In order to assure the best coverage of the metropolitan area, the region was divided into small segments of similar size. A random sample of those segments was taken and a number of questionnaires were then randomly assigned to each of them. The field supervisor would then decide which houses to survey in each locality. If the person at the door did not meet our criteria, the house next door was surveyed. A total of 602 questionnaires were completed.

Table 1 presents some descriptive statistics. The average income in Costa Rica was 160,000 colones $^{5}$ per month in 1999 , whereas the average income of the $10^{\text {th }}$ decile is around 600,000 . Our sampled income distribution seems to fit this description, given the exclusion of low-income and rural families from our sample. The gender composition of our sample is again simply the reflection of our sampling strategy, which required the respondent to be currently employed. Of particular interest is the extremely high number of respondents who usually use

\footnotetext{
${ }^{5}$ 1USD corresponds to approximately 300 colones.
} 
the car to go to work, which posses an additional challenge for policy-makers. A large share of the respondents also stated that they sometimes need the car in their line of work.

Table 1: Sample statistics

\begin{tabular}{l|cc}
\hline \multicolumn{2}{c}{ Variable } & Frequency \\
\hline \multirow{2}{*}{ Income in colones } & $0-200,000$ & $31.6 \%$ \\
& & \\
\cline { 2 - 3 } & $200,001-400,000$ & $40.3 \%$ \\
\cline { 2 - 3 } & $400,001-600,000$ & $18.3 \%$ \\
\cline { 2 - 3 } & $600,001-800,000$ & $5.7 \%$ \\
\cline { 2 - 3 } Gender & $800,001+$ & $3.5 \%$ \\
\hline \multirow{2}{*}{ Usual travel mode } & Male & $77.2 \%$ \\
\cline { 2 - 3 } & Female & $22.8 \%$ \\
\hline Car needed at work & Car & $90.7 \%$ \\
& Bus & $39 \%$ \\
\hline & Yes & $60.1 \%$ \\
\hline
\end{tabular}

The questionnaire consisted of three parts. The first part contained a number of questions regarding their present work trips. The second part of the survey contained the choice experiment. Before the actual experiment was conducted, the enumerator carefully explained each of the attributes in the choice experiment. The respondent also received a written summary of the attributes. The last part of the survey contained questions regarding the respondent's socio-economic status and debriefing questions regarding the choice experiment.

Several focus groups, a pilot study and discussions with experts preceded the final design of the experiment. These aimed at identifying the relevant alternatives, their attributes and realistic attribute levels required to create the profiles. Two important conclusions of these discussions were the need to customize some of the attributes, particularly travel time and cost per trip, and the possibility of restricting the number of alternatives to only two: car and bus. All of the attributes selected are factors that a policy maker can directly affect through, for example, a gasoline tax or, indirectly, through contracts with the bus companies, for example. Local newspapers have been discussing the imperative need for a solution to the problem of public and private transportation. Different alternatives have been discussed and described, in particular the program for increasing the quality of bus services. This gave extra realism to our survey.

The selected attributes for the car alternative are: (1) operating costs, (2) travel time per trip and (3) parking cost. The selected attributes for the bus alternative are: (1) travel time, (2) bus fare per trip, (3) punctuality, (4) distance to bus stop, (5) frequency of departures and (6) comfort and security. These attributes and their levels are presented in Table 2. 
Table 2. Attributes and attribute levels

\begin{tabular}{|c|c|c|}
\hline \multicolumn{2}{|c|}{ Attribute } & Levels \\
\hline \multicolumn{2}{|c|}{ Travel cost car, per trip } & i. Same as today, ii. $25 \%$ increase, iii. $40 \%$ increase \\
\hline \multicolumn{2}{|c|}{ Bus fare, per trip } & i. 50 colones, ii. 100 colones \\
\hline \multicolumn{2}{|c|}{ Parking cost } & i. Free parking, ii. 400 colones per day \\
\hline \multirow[t]{2}{*}{ Travel time } & Car & i. Same as today \\
\hline & Bus & $\begin{array}{l}\text { i. Same time as car, ii. } 20 \text { minutes longer than car, iii. } 30 \text { minutes longer than } \\
\text { car, iv. } 40 \text { minutes longer than car }\end{array}$ \\
\hline \multicolumn{2}{|l|}{ Punctuality } & $\begin{array}{l}\text { i. The bus is always on time, ii. The bus sometimes is more than } 15 \text { minutes } \\
\text { late }\end{array}$ \\
\hline \multirow{2}{*}{\multicolumn{2}{|c|}{$\begin{array}{l}\text { Distance to bus stop } \\
\text { No. of departures }\end{array}$}} & i. 10 minutes, ii. 15 minutes, iii. 20 minutes \\
\hline & & Every i. 5 minutes, ii. 10 minutes, iii. 15 minutes \\
\hline \multicolumn{2}{|c|}{ Comfort and security } & i. Same as today, ii. The Program for Quality Improvement is implemented \\
\hline
\end{tabular}

The cost per trip and travel time for the car alternative, and travel time by bus, were customized to the current situation and thus not presented in Table 2. ${ }^{6}$ Questions regarding the distance to work, type of fuel used and the travel time by car were asked at the beginning of the survey. The enumerator then filled in the relevant information in the choice experiment. The cost per car trip in colones was calculated based on conversion tables, which included the percentage increase in gasoline price. The punctuality attribute was defined and explained such that it was not related to frequency of departures. For a high frequency service, one could argue that punctuality is not important since travelers prefer to go to the bus stop spontaneously. Nevertheless, it was explained that delays in the bus imply that for at least 15 minutes there was no bus stopping, irrespective of the frequency of departures. This is more in line with the actual situation. The Program for Quality Improvement, currently under study by the government, was carefully described. If this program were implemented, it would bring an increase in the quality of the service, including more comfortable buses, and higher security both onboard and at improved bus stops.

The choice situations were constructed with a linear D-optimal design using SAS (see e.g. Kuhfeld, 2001). Since there are only two alternatives, we treated travel time in terms of the difference between the two modes. The eight attributes were combined into 24 choice sets. These where then divided into three groups of eight choice situations. Consequently, each respondent answered eight choice sets. In each choice set they were to choose between going to work by car or by bus, given the combination of attributes.

Since task complexity, learning and fatigue effects are regularly mentioned as criticisms of this type of experiments, we conduct a test of the stability of preferences. Following Carlsson and Martinsson (2001), a simple test was incorporated into the design. This test consisted of surveying half of the respondents with the choice sets in the order $\{\mathrm{A}, \mathrm{B}\}$ and the other half in the order $\{\mathrm{B}, \mathrm{A}\} .^{7} \mathrm{~A}$ test for stability was performed by comparing the preferences estimated

\footnotetext{
${ }^{6}$ In principle, the best way to customize travel time for the bus option would have been to define percentage increases relative to the car alternative. Nevertheless, we feared that this would be too demanding for the enumerator and possibly for the respondent as well. The levels chosen, in terms of absolute differences, where then the most reasonable ones, based on the results of focus groups. The average travel time for trips to work by bus and car are 60 and 25 minutes, respectively, for the individuals in our sample.

7 "A" refers to the original first 4 choice sets, and "B" to the original last 4 choice sets in each experiment.
} 
for the choices in subset $A$, when it was given in the sequence $\{A, B\}$, with the preferences obtained when the choices in subset $A$ were given in the sequence $\{B, A\}$. This can be formally tested in a likelihood ratio test between the pooled model of the choices in subset A and the separate groups. A similar test can be performed for subset B. If the pooled model cannot be rejected, we can reject the hypothesized presence of the effects mentioned above. Based on the standard MNL, the hypothesis of stable preferences cannot be rejected. ${ }^{8}$

The survey also included debriefing questions, mainly intended to identify respondents who did not like (protestors) or did not understand the experiment. Of all 602 interviewed individuals, 3.8\% (23 individuals) expressed a negative perception or understanding of the experiment. These questionnaires are excluded from the estimations presented in the next section.

\section{Results}

We estimate two Random Parameter Logit models (RPL), in addition to the multinomial logit model. The two RPL models are: one with the attributes independently normally distributed and one with the attributes independently lognormally distributed. In both RPL models the cost attributes are kept fixed for several reasons: (i) we wish to restrict the cost variables to be non-positive for all respondents, hence a normal distribution is not recommended, (ii) a lognormal distribution, which would restrict the sign of the variable, can result in extremely high values-of-time estimates, since values of the cost attribute close to zero are possible (Revelt and Train, 1998), and (iii) the distribution of the marginal value of time is simply the distribution of the time attribute.

The attribute "distance to the bus stop" was consistently insignificant and caused problems with convergence for some models, and was therefore dropped from the analysis. ${ }^{9}$ Both specifications included a mode specific intercept for car; in the normal specification the coefficient is fixed, while normally distributed in the model with lognormally distributed attributes. ${ }^{10}$ Another important part of the model is a variable capturing state dependence or inertia in travel behavior. This variable was specified as a dummy variable equal to one if the respondent usually uses the car when traveling to work. In both random parameter models, a fixed state dependence variable could not be rejected in a likelihood ratio test. Furthermore, a number of individual characteristics are included as fixed coefficients. These are (i) need car, indicating whether the respondent sometimes needs his/her own car in the line of work, (ii) the respondent's income and (iii) the respondent's age.

\footnotetext{
${ }^{8}$ The statistic is equal to 14.76 , which is $\chi^{2}$-distributed with 14 degrees of freedom

${ }^{9}$ This variable was not significant in the pilot study either, although it was mentioned several times during the focus groups. We tried to change the explanation of this attribute in order to have individuals make a trade-off with this characteristic also. There are several explanations why this attribute turns out to be insignificant. First, the respondents may actually not see this attribute as important, or the choice experiment may have been too difficult and therefore many respondents chose not to focus on all attributes, including the distance to the nearest bus stop. Alternatively, it may not have been thought of as credible that the government could actually change the distance to the bus stop by changing the routes. If this was the case, it is an important issue to consider in future applications of choice experiments in developing countries.

${ }^{10}$ The model with normally distributed attributes did not converge when we included a normally distributed intercept.
} 
In Table 3 we present the results for the three estimated models. The models were estimated using Limdep 7.0.2, and simulated maximum likelihood, based on Halton draws and 500 replications.

Table 3. Econometric results

\begin{tabular}{|c|c|c|c|c|c|c|c|}
\hline & \multirow{2}{*}{$\frac{\text { MNLogit }}{\text { Coeff }}$} & \multicolumn{2}{|c|}{ RPL (normal) } & \multicolumn{4}{|c|}{ RPL (lognormal) } \\
\hline & & Coeff. & Coeff. Std. & Coeff & Coeff Std. & Median & Mean \\
\hline Constant: Car & $\begin{array}{r}0.098 \\
(0.235) \\
\end{array}$ & $\begin{array}{r}-1.427 \\
(0.740)^{\mathrm{c}} \\
\end{array}$ & Fixed & $\begin{array}{r}-0.488 \\
(0.814) \\
\end{array}$ & $\begin{array}{r}2.594 \\
(0.266)^{\mathrm{a}} \\
\end{array}$ & $\begin{array}{r}-0 \\
(0 . \\
\end{array}$ & \\
\hline Time (minutes): Car & $\begin{array}{r}-0.023 \\
(0.004)^{\mathrm{a}} \\
\end{array}$ & $\begin{array}{r}-0.032 \\
(0.019)^{\mathrm{b}} \\
\end{array}$ & $\begin{array}{r}0.066 \\
(0.011)^{\mathrm{a}} \\
\end{array}$ & $\begin{array}{r}-3.221 \\
(0.496) \\
\end{array}$ & $\begin{array}{r}0.430 \\
(0.467) \\
\end{array}$ & $\begin{array}{r}-0.040 \\
(0.020)^{\mathrm{b}} \\
\end{array}$ & $\begin{array}{r}-0.044 \\
(0.016)^{\mathrm{a}} \\
\end{array}$ \\
\hline Time (minutes): Bus & $\begin{array}{r}-0.017 \\
(0.003)^{\mathrm{a}} \\
\end{array}$ & $\begin{array}{r}-0.053 \\
(0.006)^{\mathrm{a}} \\
\end{array}$ & $\begin{array}{r}0.043 \\
(0.006)^{\mathrm{a}} \\
\end{array}$ & $\begin{array}{r}-3.187 \\
(0.151) \\
\end{array}$ & $\begin{array}{r}0.988 \\
(0.208)^{\mathrm{a}} \\
\end{array}$ & $\begin{array}{r}-0.042 \\
(0.006)^{\mathrm{a}} \\
\end{array}$ & $\begin{array}{r}-0.067 \\
(0.018)^{\mathrm{a}} \\
\end{array}$ \\
\hline Cost (colones): Car & $\begin{array}{r}-0.001 \\
(0.0003)^{\mathrm{a}} \\
\end{array}$ & $\begin{array}{r}-0.003 \\
(0.090)^{\mathrm{a}} \\
\end{array}$ & Fixed & $\begin{array}{r}-0.003 \\
(0.0008)^{\mathrm{a}} \\
\end{array}$ & Fixed & & \\
\hline Cost (colones): Bus & $\begin{array}{r}-0.001 \\
(0.002) \\
\end{array}$ & $\begin{array}{r}-0.002 \\
(0.249) \\
\end{array}$ & Fixed & $\begin{array}{r}-0.002 \\
(0.002) \\
\end{array}$ & Fixed & & \\
\hline Parking (dummy) & $\begin{array}{r}-0.190 \\
(0.075)^{\mathrm{b}} \\
\end{array}$ & $\begin{array}{r}-0.214 \\
(0.151) \\
\end{array}$ & $\begin{array}{r}1.446 \\
(0.204)^{\mathrm{a}} \\
\end{array}$ & $\begin{array}{r}-1.935 \\
(0.607) \\
\end{array}$ & $\begin{array}{r}1.522 \\
(0.313)^{\mathrm{a}} \\
\end{array}$ & $\begin{array}{r}-0.144 \\
(0.088)^{\mathrm{c}} \\
\end{array}$ & $\begin{array}{r}-0.460 \\
(0.490) \\
\end{array}$ \\
\hline Punctuality (dummy) & $\begin{array}{r}0.639 \\
(0.076)^{\mathrm{a}} \\
\end{array}$ & $\begin{array}{r}1.111 \\
(0.181)^{\mathrm{a}} \\
\end{array}$ & $\begin{array}{r}1.864 \\
(0.228)^{\mathrm{a}} \\
\end{array}$ & $\begin{array}{r}-0.495 \\
(0.253) \\
\end{array}$ & $\begin{array}{r}1.325 \\
(0.181)^{\mathrm{a}} \\
\end{array}$ & $\begin{array}{r}0.610 \\
(0.154)^{\mathrm{a}} \\
\end{array}$ & $\begin{array}{r}1.468 \\
(0.701)^{\mathrm{b}} \\
\end{array}$ \\
\hline $\begin{array}{l}\text { No. of departures } \\
\text { (units) }\end{array}$ & $\begin{array}{r}0.031 \\
(0.011)^{\mathrm{a}} \\
\end{array}$ & $\begin{array}{r}0.006 \\
(0.030) \\
\end{array}$ & $\begin{array}{r}0.240 \\
(0.030)^{\mathrm{a}} \\
\end{array}$ & $\begin{array}{r}-3.225 \\
(0.646) \\
\end{array}$ & $\begin{array}{r}1.053 \\
(0.456)^{\mathrm{b}} \\
\end{array}$ & $\begin{array}{r}0.040 \\
(0.026) \\
\end{array}$ & $\begin{array}{r}0.069 \\
(0.019)^{\mathrm{a}} \\
\end{array}$ \\
\hline $\begin{array}{l}\text { Quality program } \\
\text { (dummy) }\end{array}$ & $\begin{array}{r}0.054 \\
(0.075) \\
\end{array}$ & $\begin{array}{r}0.171 \\
(0.132) \\
\end{array}$ & $\begin{array}{r}0.357 \\
(0.312) \\
\end{array}$ & $\begin{array}{r}-2.928 \\
(1.458) \\
\end{array}$ & $\begin{array}{r}1.386 \\
(0.447)^{\mathrm{a}} \\
\end{array}$ & $\begin{array}{r}0.054 \\
(0.078) \\
\end{array}$ & $\begin{array}{r}0.140 \\
(0.289) \\
\end{array}$ \\
\hline \multicolumn{8}{|c|}{ Non-random socio-demographic characteristics } \\
\hline State dependence & $\begin{array}{r}1.755 \\
(0.111)^{\mathrm{a}} \\
\end{array}$ & & $\begin{array}{r}4.300 \\
(0.518)^{\mathrm{a}} \\
\end{array}$ & & $\begin{array}{r}4.266 \\
(0.555)^{\mathrm{a}} \\
\end{array}$ & & \\
\hline Need car at work & $\begin{array}{r}0.553 \\
(0.081)^{\mathrm{a}} \\
\end{array}$ & & $\begin{array}{r}0.791 \\
(0.307)^{\mathrm{a}} \\
\end{array}$ & & $\begin{array}{r}1.043 \\
(0.348)^{\mathrm{a}} \\
\end{array}$ & & \\
\hline Income & $\begin{array}{r}0.041 \\
(0.011)^{\mathrm{a}} \\
\end{array}$ & & $\begin{array}{r}0.067 \\
(0.041)^{\mathrm{c}} \\
\end{array}$ & & $\begin{array}{r}0.050 \\
(0.046) \\
\end{array}$ & & \\
\hline Age & $\begin{array}{r}-0.081 \\
(0.035)^{\mathrm{b}} \\
\end{array}$ & & $\begin{array}{r}-0.094 \\
(0.139) \\
\end{array}$ & & $\begin{array}{r}-0.146 \\
(0.154) \\
\end{array}$ & & \\
\hline Log-likelihood & 2226 & & 1695 & & 1662 & & \\
\hline Pseudo R2 & 0.31 & & 0.47 & & 0.48 & & \\
\hline
\end{tabular}

Standard errors in parentheses

a significant at $1 \%$ level

b Significant at $5 \%$ level

c Significant at $10 \%$ level

Columns 3 and 4 give the estimated coefficients for the model with the attributes normally distributed and columns 5 and 6 for the model with the attributes lognormally distributed. The last two columns in the table present the estimated median and mean of $\beta_{k}$ for the lognormal distribution. The two RPL models have a substantially higher pseudo- $\mathrm{R}^{2}$ compared to the MNL model. The MNL is a restricted version of the two RPL models, in which all the coefficients are deterministic. In a likelihood ratio test we can reject the restrictions imposed 
by the MNL model. ${ }^{11}$ The two RPL models give similar results in terms of the significance of coefficient and standard deviations estimates. ${ }^{12}$ The only differences are that the mean coefficient for Number of departures is insignificant in the normal model while significant in the lognormal model, that the estimated standard deviation for Travel time by car is only significant in the normal model and finally that the estimated standard deviation for the Quality program is only significant in the lognormal model. Most of the standard deviations are significant, reflecting heterogeneity in the underlying preference structure. There is a fundamental difference between the two Random Parameter Models in this respect. The lognormal distribution ensures that all individuals have the same coefficient signs, while the normal distribution implies that some individuals will have the opposite coefficient signs. Since the estimated standard deviations are large relative to the estimated mean coefficients in the RPL model with normal distribution, a relatively large fraction of the respondents actually has the reverse sign of the preference for the different attributes. This is perhaps not a desirable feature of the model and as such, a justification for preferring the lognormal model.

In the lognormal model, all attributes except the Bus fare, the Quality program and Parking, have significant mean effects. ${ }^{13}$ The relative importance of the level-of-service attributes is revealed by the estimates of the mean in columns (3) and (8) for the normal and lognormal models, respectively, for those attributes that share the same unit of measurement. For example, Punctuality has relatively a much higher mean effect on the utility derived from a bus trip than the Quality program.

For the car mode, Travel time and Cost per trip are the significant determinants of the mode choice. It is surprising that Parking cost is not significant, given our discussion in section 2. A possible explanation for this result is that the levels presented in the experiment might have been regarded as too low. The definition of the levels for the parking attribute proved to be an evasive task throughout the construction of the experiment. Although parking in the city can be regarded as free, there is an informal system of car-watchers (mostly children and indigents) who charge a fee for their service. For the bus mode all attributes except for the Cost per trip and the Quality program are significant determinants of the mode choice, although Number of departures is not significant in the normal model. This indicates that the important characteristic of the bus mode is the overall travel time.

An important variable in our model is the state dependence variable, which is highly significant. This variable captures a strong inertia in the use of the car for those individuals already using it, and it has important policy implications. Another way in which we model heterogeneous preferences is by including socio-demographic information about the respondents. As expected, those individuals who sometimes need the car at work are more likely to choose the car mode in the choice experiment. In the MNL model, both the income

\footnotetext{
${ }^{11}$ For the RPL(normal) and RPL(lognormal) models, the test statistics are 1062 which is $\chi^{2}$-distributed with 6 degrees of freedom, and 1128 which is $\chi^{2}$ with 7 degrees of freedom, respectively.

${ }^{12}$ The significance of the constant term $\left.b_{k}\right)$ in the log-normally distributed coefficients is not reported since the only reasonable test of significance for this parameter is a test of negative infinity. In any case, the standard errors of these estimated coefficients are small compared to the parameters.

${ }^{13}$ For large samples, and under quite general conditions, the sample mean of a sequence of random variables converges to a normal distribution even though the parent distribution is not normal. A one-tail t-student test can therefore be applied on the means to test the hypothesis $\beta^{\text {mean }}=0$, versus $\beta^{\text {mean }}>0$.
} 
and the age of the respondent are highly significant. This significance is reduced in the RPL models. The positive coefficient for income is in line with other studies that expectedly indicate that higher income individuals are less likely to take the bus, since they experience a higher cost of traveling time.

\section{Analysis of Results}

In this section we explore the responsiveness of modal choice to changes in the attributes. The most interesting issue is to determine which attributes are more likely to affect the choice of transport mode. For this purpose we calculate the aggregate elasticities and marginal effects for each attribute and we estimate the value-of-time for each mode. Reduced congestion not only reduces emissions, but also reduces travel time for both car and bus users. The estimates of the value-of-time provide information about the potential gains from such policies. The benefits from shorter travel time may actually be as important as the benefits from reduced emissions.

Since the two different RPL models give similar elasticities and marginal effects, we only report the results for the model with the attributes having a lognormal distribution. The disaggregate direct and cross elasticity for attribute $x_{i}$ for individual $q$ is given by

$$
\begin{aligned}
& \frac{\partial P_{q}(i)}{\partial x_{i q}} \frac{x_{i q}}{P_{q}(i)}=\int P_{q}(i \mid \beta)\left[1-P_{q}(i \mid \beta)\right] \frac{\partial U_{i q}}{\partial x_{i q}} f(\beta) d \beta \frac{x_{i q}}{P_{q}(i)} \\
& \frac{\partial P_{q}(j)}{\partial x_{i q}} \frac{x_{i q}}{P_{q}(j)}=\int P_{q}(j \mid \beta) P_{q}(i \mid \beta) \frac{\partial U_{i q}}{\partial x_{i q}} f(\beta) d \beta \frac{x_{i q}}{P_{q}(j)}
\end{aligned}
$$

The aggregate elasticities are computed as a weighted average of the individual elasticities using the choice probabilities as weights (see Ben-Akiva and Lerman, 1985). Table 4 reports the estimated elasticities and marginal effects. ${ }^{14}$

Table 4: Average elasticities and marginal effects (times 100) for the car and bus modes. RPL model with Lognormal distribution

\begin{tabular}{l|c|r|r|r} 
& \multicolumn{2}{|c|}{ Average Elasticities } & \multicolumn{2}{c}{ Average marginal effects } \\
\hline Increase in travel time for the car mode & Direct (Car) & Cross (Bus) & Direct (Car) & Cross (Bus) \\
\hline Increase in cost per car trip & -0.093 & 0.319 & -6.854 & 8.282 \\
\hline Increase in parking costs for car & -0.064 & 0.219 & -4.613 & 6.027 \\
\hline & -0.020 & 0.069 & -1.516 & 1.673 \\
\hline Decrease in travel time for the bus mode & Cross (Car) & Direct (Bus) & Cross (Car) & Direct (Bus) \\
\hline Decrease in cost per bus trip & -0.136 & 0.468 & -9.855 & 12.813 \\
\hline Increase in punctuality & -0.014 & 0.049 & -1.055 & 1.239 \\
\hline Increase in frequency & -0.059 & 0.202 & -4.280 & 5.461 \\
\hline Increase in quality & -0.047 & 0.161 & -3.524 & 3.964 \\
\hline
\end{tabular}

\footnotetext{
${ }^{14}$ Parking, punctuality and quality are dummy variables, so the reported elasticities and marginal effects are only approximations.
} 
The elasticities and marginal effects are generally low, mainly due to the effect of state dependence and the limited adjustment to the policies permitted in our study, due to the assumptions of given number of trips, and fixed origin and destination. This is expected, and is in line with other similar studies (see for example Bhat, 2000 and 1998; and Swait and Eskeland, 1995 for a LDC application using revealed preference data). Travel time for bus and car have the highest elasticities and marginal effects. A hypothetical $10 \%$ decrease in average travel time by bus (corresponding to an average reduction of 6 minutes) would reduce the probability of car use by $1.36 \%$.

The elasticity and marginal effect of the cost per car trip is much higher than the elasticity and marginal effect of the cost per bus trip, and parking cost is less important than both cost per car trip and per bus trip. As we have discussed before, punctuality and frequency of the bus service both have a larger impact on the choice of mode than the Quality Improvement Program. This is also an indication of the importance of travel time, since frequency and punctuality have and impact on overall travel time.

Our analysis allows us to reach several conclusions from a policymaking perspective. First, the model shows an important inertia in travel behavior. The car mode certainly has several advantages in terms of comfort, travel route timing flexibility and safety, among others, and our results confirm that breaking the travel pattern of a car user is difficult, albeit not impossible, as is commonly believed in Costa Rica. A reduction in travel time for the bus mode emerges as the most important element in a program aimed at attracting commuters towards public transport and away from the private mode. Consequently, measures such as exclusive bus lanes, faster and more accurate connections and traffic light priority, can have an impact on the use of private transport. On the other hand, subsidized bus fares seem to have very low effectiveness according to our analysis. Subsidies should instead be linked to better service, particularly regarding punctuality and frequency of departures, which further reduce overall travel time. Alternatively, the low direct elasticity of bus fares indicates the feasibility of creating a bus system that is more expensive, but faster and with better service, which would target the middle class travelers sampled in our study. Of the monetary incentives that could be used to discourage private transportation, increases in parking costs at work do not seem to be as effective as expected. Its mean effect is not significantly different than zero, and the elasticity of car use with respect to parking costs is correspondingly very low. Due to the reasons mentioned in the previous section, we prefer not to draw a strong conclusion from this result. On the other hand, contrary to public perception, increases in cost per car trip do have an effect on modal substitution, although this effect is rather small.

Finally, the (average) marginal value of time is calculated as the ratio of the coefficient for travel and the coefficient of travel cost by car. The value of time is related to the value of working time for individuals traveling to work. In our sample, the average wage per hour is around 2,000 colones. Table 5 reports the estimated average marginal values of time for all three models. The confidence intervals are based on 9,000 replications of the Krinsky-Robb (1986) method. 
Table 5: Average Value of Time, $90 \%$ confidence interval

\begin{tabular}{|l|c|c|c|c|}
\hline & MNL & RPL (normal) & \multicolumn{2}{|c|}{ RPL (lognormal) } \\
\hline & & & Mean & Median \\
\hline Value of time in bus (col/hour) & 949 & 1005 & 1394 & 856 \\
& $(602-4640)$ & $(666-1820)$ & $(795-3109)$ & $(536-1715)$ \\
\hline Value of time in car (col/hour) & 1291 & 614 & 908 & 827 \\
& $(534-2806)$ & $(27-1878)$ & $(441-3171)$ & $(291-2952)$ \\
\hline
\end{tabular}

The differences between the two Random Parameter Models become clearer here. Due to the assumption of a log-normal distribution, the estimated mean value-of-time is higher in the lognormal model compared to the normal model, in particular for the value of time when traveling by bus. The willingness to pay for reduced travel time in both modes is high, around 40 to $50 \%$ of the average hourly wage in our sample. This is in line with previous studies (Small, 1992). Further, the confidence intervals are very large, in particular for the lognormal model. In the Random Parameter Models, the willingness to pay for reduced travel time is higher for the bus mode than for the car mode. This result is expected since the disutility of the time spent traveling by bus is likely to be higher. These results show that reductions in travel time due to reduced congestion can have substantial benefits for our sample population.

\section{Conclusion}

In general, the results indicate that model substitution is sensitive to the characteristics and performance of each mode. In particular, travel time for both modes and travel cost for car are the most important determinants of mode choice. Our estimates for the average elasticities and marginal effects are rather small. This is in line with other studies, and is partly the result of their short run perspective. Since the aim is to determine which characteristics are more relevant to achieving a switch from private to public modes of transportation, we rather concentrate on the relative importance of each attribute. We therefore conclude that a program aimed at reducing congestion and pollution during peak hours should focus on increasing the cost of private transport and providing faster and more reliable public transport. The possibility of separating public transport by creating a parallel service that provides a more expensive but faster service, is one potential alternative to detract customers from private transportation. As mentioned in section 3, the Costa Rican government is currently redesigning the system of public transportation. Our study sheds light on the most important features required by that system if it is to attract travelers from private modes. Specifically, special emphasis has to be put on designing routes and exclusive bus lanes, and providing traffic priority for buses, faster connections, and more frequent and reliable departures, among other measures intended to reduce travel time. Finally, our estimates of the willingness to pay for reduced travel time in both modes show that large benefits can be obtained from a program aimed at reducing congestion. 


\section{References}

Alfaro, M. (1999), "Calidad del Aire en San José y otros Puntos del Gran Área Metropolitana: Informe 1999', Programa de Estudios de Calidad del Aire, Universidad Nacional, Costa Rica.

Alpizar, F., F. Carlsson and P. Martinsson (2001), "Using Choice Experiments for Non-Market Valuation", Working Paper in Economics No. 52, Department of Economics, Gothenburg University.

Ben-Akiva, M. and S. Lerman (1985), Discrete Choice Analysis, Cambridge Mass.: MIT Press.

Bhat, C. (1998), "Accommodating Variations in Responsiveness to Levelof-Service Measures in Travel Mode Choice Modeling", Transport Research A. 32: 495-507.

Bhat, C. (2000), "Incorporating Observed and Unobserved Heterogeneity in Urban Work Travel Mode Choice Modeling', Transportation Science 34: 228-238.

Carlsson, F. and P. Martinsson (2001), "Do Hypothetical and Actual Marginal Willingness to Pay Differ in Choice Experiments? - Application to the Valuation of the Environment", Journal of Environmental Economics and Management 41: 179-192.

De Borger, B., I. Mayeres, S. Proost, and S. Wouters (1996), "Optimal Pricing of Urban Passenger Transport: A Simulation Exercise for Belgium", Journal of Transport Economics and Policy 30: 31-54.

De Borger, B. and S. Wouters (1998), "Transport Externalities and Optimal Pricing and Supply Decisions in Urban Transportation: A Simulation Analysis for Belgium", Regional Science and Urban Economics 28: 163-197.

Echeverría, J. and G. Solórzano (2000), "Impacto Ambiental de la Importación de Vehículos en Costa Rica: Un Análisis Preliminar" Centro Científico Tropical, Costa Rica.

Eskeland, G. and S. Devarajan (1996), "Taxing Bads by Taxing Goods: Pollution Control with Presumptive Charges", Directions in Development, The World Bank, Washington D.C.

Eskeland, G. and E. Jimenez (1992), "Policy Instruments for Pollution Control in Developing Countries', The World Bank Research Observer 7: 145-170.

Fullerton, D. and S. West (2001), "Can Taxes on Cars and on Gasoline Mimic an Unavailable Tax on Emissions?", Journal of Environmental Economics and Management , forthcoming.

Harrington, W., Krupnick, A. and A. Alberini (1998), "Overcoming Public Aversion to Congestion Pricing", Discussion Paper 98-27, Resources for the Future.

Huber, R., J. Ruitwnbeek and R. Serao da Motta (1998), "Market Based Instruments for Environmental Policymaking in Latin America and the Caribbean; Lessons from Eleven Countries", World Bank Discussion Paper No. 381, The World Bank.

Jiménez, G. (1997), "Análisis del Impacto del Ecomarchamo", School of Civil Engineering, University of Costa Rica.

Johnstone, N. and K. Karousakis (1999), "Economic Incentives to Reduce Pollution from Road Transport: The Case for Vehicle Characteristics Taxes", Transport Policy 6: 99-108.

Johansson, O. (1997), "Optimal Road-Pricing: Simultaneous Treatment of Time Losses, Increased Fuel Consumption, and Emissions", Transportation Research D 2: 77-78.

Krinsky, L. and A.L. Robb (1986), "On Approximating the Statistical Properties of Elasticities", Review of Economics and Statistics 68: 715-719.

Kuhfeld, W. (2001), "Multinomial Logit, Discrete Choice Modeling. An Introduction to Designing Choice Experiments, and Collecting, Processing and Analyzing Choice Data with SAS", SAS Institute TS-643.

Lancaster, K. (1966), “A New Approach to Consumer Theory”, Journal of Political Economy 74: $217-231$. 
Louviere, J., D. Hensher and J. Swait (2000), Stated Choice Methods. Analysis and Application, Cambridge: Cambridge University press.

McFadden, D. (1974), "Conditional Logit Analysis of Qualitative Choice Behavior", in Zarembka, P., ed., Frontiers in Econometrics, New York: Academic Press.

Ministry of Health (1997), "Resultados de la Encuesta sobre Principales Causas de Consulta Externa en Costa Rica", Ministry of Health, Costa Rica.

Ministry of Public Infrastructure and Transport (1999), "Reorganización del Transporte Público Colectivo en el Área Metropolitana de San José", Ministry of Public hfrastrucutre and Transport, Costa Rica.

O’Connor, D. (1999), “Applying Economic Instruments in Developing Countries: From Theory to Implementation", Environment and Development Economics 4: 91-100.

Polak, J. and P. Jones (1997), "Using Stated-Preference Methods to Examine Travelers Preferences and Responses", in Stopher, P. and M. Lee-Gosselin, eds., Understanding Travel Behavior in an Era of Change, Oxford: Pergamon.

Proyecto Estado de la Nación (1999). "Estado de la Nación", San José, Costa Rica.

Pujol, R. (1996), "The Spatial Structure of Urban and Metropolitan Regions as a Critical Variable in the Long Run Reduction of Urban Air Pollution”, ProDus, Costa Rica

RECOPE (1999), "Actualización de la Información del Parque Automotor Costarricense", Dirección de Estudios de Demanda Energética, Costa Rica.

Revelt, D. and K. Train (1998), "Mixed Logit with Repeated Choices: Households' Choices of Appliance Efficiency Level", Review of Economics and Statistics, 80: 647-657.

Small, K.A. (1982), "The Scheduling of Consumer Activities: Work Trips", American Economic Review 72: 467-479.

Small, K.A. (1992), Urban Transportation Economics, Luxembourg: Harwood Academic Publishers.

Sterner, T. (1994), "The Price of Petroleum Products", in Sterner, T., ed., Economic Policies for Sustainable Development, Kluwer Academic Publishers.

Swait, J. and G. Eskeland (1995), 'Travel Mode Substitution in Sao Paulo: Estimates and Implications for Pollution Control', Policy Research Working Paper 1437, The World Bank.

Thomson, J.M. (1998), 'Reflections on the Economics of Traffic Congestion', Journal of Transport Economics and Policy 32: 93-109.

Thurstone, L. (1927), "A Law of Comparative Judgment”, Psychological Review 4: 273-86.

Train, K. (1998), "Recreation Demand Models with Taste Differences over People", Land Economics 74: 230-239.

Train, K. (1999), "Halton Sequences for Mixed Logit", Working Paper Department of Economics, University of California, Berkeley.

Willson, R. and D. Shoup (1990), "Parking Subsidies and Commuter Mode Choic e: Assessing the Evidence", Transportation 16: 53-69.

World Bank (1996), "Sustainable Transport, Priorities for Policy Reform”, Washington, D.C: The World Bank. 